\title{
Érythrasma axillaire et inguinal
}

\author{
Irene López Riquelme MD, Elisabeth Gómez Moyano MD PhD
}

Citation : CMAJ 2021 October 4;193:E1535. doi : 10.1503/cmaj.210310-f

Voir la version anglaise de l'article ici : www.cmaj.ca/lookup/doi/10.1503/cmaj.210310

$\mathbf{U}$

$\mathrm{n}$ homme de 50 ans a consulté en dermatologie pour un problème de lésions prurigineuses aux aisselles et à l'aine depuis 1 an. Son médecin de famille, qui soupçonnait un intertrigo fongique, l'avait traité sans succès au moyen d'une préparation antifongique topique (Ciclopirox Olamine). À l'examen physique, nous avons observé des plaques squameuses érythémateuses brunâtres bien délimitées, aux aisselles et à l'aine, des 2 côtés (figure 1). Pour écarter le diagnostic de mycose superficielle, nous avons examiné des échantillons de peau affectée obtenus par grattage en microscopie directe après préparation à l'hydroxyde de potassium. Nous n'avons trouvé aucun signe d'infection fongique et n'avons isolé aucun dermatophyte dans l'agar de Sabouraud.
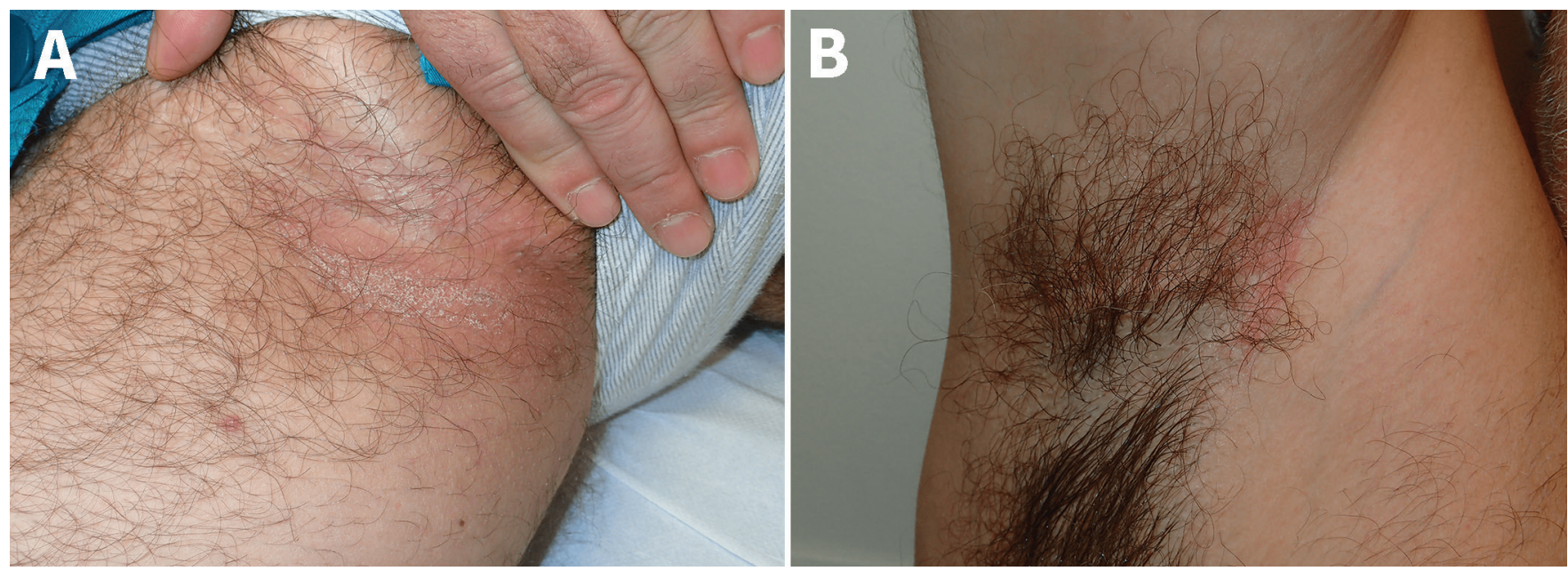

Figure 1 : Photographies d'un homme de 50 ans présentant des plaques squameuses érythémateuses brunâtres à l'aine (A) et à l'aisselle (B).

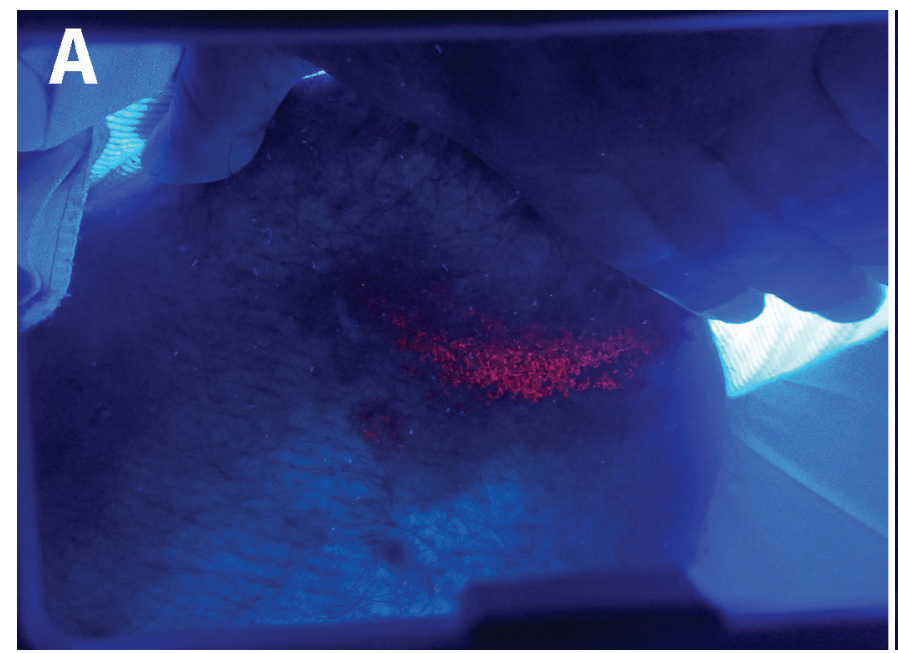

\section{B}

Figure 2 : Photographies de lésions à l'aine (A) et à l'aisselle (B) montrant une fluorescence rouge corail sous la lampe de Wood. 
Nous avons soupçonné une infection bactérienne. Sous la lampe de Wood, les lésions présentaient une fluorescence rouge corail (figure 2). La coloration de Gram a confirmé l'érythrasma, montrant des amas de bacilles dans les cellules épithéliales; Corynebacterium minutissimum a été isolée dans les cultures. Nous avons prescrit du gel d'érythromycine par voie topique 2 fois par jour, et les lésions cutanées se sont résorbées en 2 semaines.

L'érythrasma est une infection superficielle causée par Corynebacterium minutissimum. Même s'il est plus fréquent dans les régions tropicales, on peut l'observer dans les zones tempérées chez les patients âgés, obèses ou diabétiques ${ }^{1}$. En général, l'érythrasma prend la forme de macules de couleur brunrougeâtre qui fusionnent en plaques plus volumineuses et qu'on peut confondre avec une mycose superficielle. L'absence de papulopustules satellites est un signe d'érythrasma². L'examen à la lampe de Wood facilite un diagnostic rapide en raison de la fluorescence rouge corail caractéristique due à la coproporphyrine III produite par les bactéries ${ }^{2,3}$. Propionibacterium acnes produit parfois une couleur similaire, et le genre Pseudomonas émet une fluorescence verte ${ }^{2}$. Un bain récent peut temporairement éliminer les porphyrines et rendre l'examen à la lampe de Wood négatif ${ }^{3}$. Pour confirmer le diagnostic, on peut utiliser ensemble la microscopie directe avec hydroxyde de potassium, la coloration de Gram et la culture, qui permettent de distinguer l'infection fongique de l'infection à Corynebacterium minutissimum ${ }^{1}$. Le traitement de l'érythrasma repose sur l'érythromycine administrée soit par voie topique 2 fois par jour jusqu'à résolution, soit par voie orale, à raison de $250 \mathrm{mg} 4$ fois par jour pendant 2 semaines ${ }^{1,2}$.

\section{Références}

1. Blaise G, Nikkels AF, Hermanns-Lê T, et al. Corynebacterium-associated skin infections. Int J Dermatol 2008;47:884-90.

2. Kalra MG, Higgins KE, Kinney BS. Intertrigo and secondary skin infections. Am Fam Physician 2014;89:569-73.

3. Wilson BB, Wagenseller A, Noland MM. An atypical presentation of erythrasma. J Am Acad Dermatol 2012;67:e217-8.

Intérêts concurrents : Aucun déclaré.

Cet article a été évalué par des pairs.

Les auteurs ont obtenu le consentement du patient.

Affiliation : Département de dermatologie, Hôpital régional universitaire de Málaga, Málaga, Espagne.

Propriété intellectuelle du contenu : Il s'agit d'un article en libre accès distribué conformément aux modalités de la licence Creative Commons Attribution (CC BY-NC-ND 4.0), qui permet l'utilisation, la diffusion et la reproduction dans tout médium à la condition que la publication originale soit adéquatement citée, que l'utilisation se fasse à des fins non commerciales (c.-à-d., recherche ou éducation) et qu'aucune modification ni adaptation n'y soit apportée. Voir : https://creativecommons.org/licenses/by-nc-nd/4.0/deed.fr.

Correspondance : Irene López Riquelme,

lopezriquelmeirene@gmail.com 